\title{
Analysis of the Impact of the European Funds in Andalusia in 2007-2013 Using a General Equilibrium Model
}

\author{
Manuel Alejandro Cardenete ${ }^{1}$, María del Carmen Delgado ${ }^{2}$ \\ ${ }^{1}$ Department of Economics, University Loyola Andalucía, Seville, Spain \\ ${ }^{2}$ Department of Economics, Quantitative Methods and Economic History, \\ University Pablo de Olavide, Seville, Spain \\ Email: macardenete@uloyola.es, mcdellop@upo.es
}

Received April 2, 2013; revised May 20, 2013; accepted June 15, 2013

Copyright (C) 2013 Manuel Alejandro Cardenete, María del Carmen Delgado. This is an open access article distributed under the Creative Commons Attribution License, which permits unrestricted use, distribution, and reproduction in any medium, provided the original work is properly cited.

\begin{abstract}
Ever since the accession of Spain to the European Economic Community, Andalusia has been recipient of European Funds. This paper proposes an analysis that will reveal the economic impact of the European Funds received by the Autonomous Region of Andalusia during the period 2007-2013. With this purpose, a Computable General Equilibrium (CGE) model will be implemented to assess, in different simulation scenarios, the effects of those funds on the main macroeconomic indicators. The results will highlight the significant contribution of the European Funds to the regional growth during the period analysed.
\end{abstract}

Keywords: Social Accounting Matrix; Applied General Equilibrium Model; European Regional Policy; Impact Analysis

\section{Introduction}

The fundamental objectives of the European Union are to promote economic and social progress and to eliminate disparities in living standards among Member States and regions. When Spain joined the European Union, Andalusia was classified as an Objective 1 region, having a gross domestic product (GDP) of less than 75 percent of the European Economic Community average.

According to the Directorate General of Community Funds, Objective 1 of the Structural Funds is the main priority of the cohesion policy of the European Union. In this reflects the fact that two thirds of Structural Fund appropriations (i.e., more than 135,000 million) is intended for recovery of the most disadvantaged regions, so-called Objective 1.

The convergence of the Andalusian economy to the EU regions in terms of GDP per capita in the early 90s was not expected, due to the economic climate that the region was going through. It was from the year 1994 when it experienced a positive trend towards real convergence with EU standards in terms of GDP per capita.

For this, in the period of EU funding 2007-2013 Andalusia followed in this category Objective 1. Following Cardenete, Delgado and Lima (2013) [1], we be- gin with a brief explanation of the changes in this period of EU funding in the Objective 1 regions that were renamed Convergence regions. The Spanish regions that currently belong to this category are Galicia, Castilla-La Mancha, Andalusia and Extremadura, being Extremadura the only one still complying with the below-75 percent requisite for the next programming period. In fact, the region of Andalusia already exceeded this threshold in the present period but it was finally considered among the Convergence regions because data from the beginning of the 2000s were used for its classification. This justifies the strong commitment of the region with various initiatives to improve competitiveness and the increase of its investment in $\mathrm{R}+\mathrm{D}+\mathrm{i}$ during the present period.

The European Regional Development Fund (ERDF), the European Social Fund (ESF) and the Cohesion Fund $(\mathrm{CF})^{1}$ financed this goal, being the financial envelope for Spain in 2007-2013, 35\% of the Community budget, which is the second more important budget item.

The rest of the original priority regions have also left the list, and have formed two different groups. On the

\footnotetext{
${ }^{1}$ European Agricultural Fund for Rural Development (EAFRD) finance rural developments, and the European Fisheries Fund (EFF) the expenditures linked to fishing.
} 
one hand, the group of the so-called "phasing out" regions, the ones that abandoned the category gradually: despite their still having a GDP which is below 75 percent of the EU-15 income, they are not poor in relation to the EU-27 average. These regions were subject to the "statistical effect" associated to the recalculation of the average European GDP per capita after the accession to the EU of new countries with comparatively lower income levels in 2004 and 2007. These regions are undergoing a regime transition in what concerns the withdrawal of the structural aid.

On the other hand, there are the "phasing in" regions, the ones subject to the "growth effect". Having belonged to the priority intervention group, they have experienced a dynamic reaction that has allowed them to improve their income level independently from the set of countries (EU-15 or EU-27) considered in the calculation. These regions enjoy another transitory regime associated to the second objective of the European Structural Funds, Regional Competitiveness and Employment, a budget item with a significantly lower financial weight.

The rest of Spanish regions benefits directly from this second objective. There is also a third and residual group called European Territorial Cooperation. In a parallel way, new regions belonging to countries in Central and Eastern Europe have enrolled the group of priority needs.

This paper proposes an analysis that will quantify the importance of European Funds in Andalusia during the seven-year funding period still in force (2007-2013) in terms of growth, development and convergence. The analysis will be done by implementing a Computable General Equilibrium (CGE) model, which will allow analysing, through the incorporation of the coefficients provided by the Social Accounting Matrix and of the behavioural assumption of the economic agents, the effects of those funds on consumer welfare and prices and their impact on the main macroeconomic variables.

CGE Models correct the limitations of linear models, and present a number of advantages allowing: solve nonlinear problems; estimate the economy prices endogenously, as a result of the free play of supply and demand; incorporate multiple markets, countless simulations considering different policy alternatives; analyze the structure of an economy, analyzing the direct and indirect relationships, whether or not intuitive; incorporate restrictions or specific structural variables that reflect more realistically the country's reality; incorporate imperfect competition in some or all markets and sectors; and quantify economic efficiency and distributional impacts of economic, social or environmental simultaneously.

These models are built upon the general equilibrium theories developed by Walras (1874) [2] and later improved by Arrow and Debreu (1954) [3], Wald (1951) [4] and McKenzie (1959) [5]. Given the important mathe- matical foundations of these theories, potent algorithms capable of obtaining equilibrium solutions were required. It was Scarf (1973) [6] who made this computational development possible, opening the door for works like those by Whalley $(1975,1977)[7,8]$ and Shoven $(1976)$ [9], among others, where the so-called CGE models were presented as a tool allowing the assessment of public policies and the implementation of comparative statics exercises. Authors as Narayan (2003) [10] and Llop and Manresa (2004) [11] used these models to analyse different issues.

The development of these models in order to analyse the economic impact of the European Funds across regions is present in works such as that of Lima and Cardenete $(2007,2008)[12,13]$, which proposed a CGE model to assess the impact of the FEDER Funds on the Andalusian economy through the Social Accounting Matrices for 1990, 1995 and 1999. Lima, Cardenete and Usabiaga (2010) [14] expanded this analysis by presenting a CGE model which simulated the behaviour of the main nominal and real indicators of the regional economy in case Andalusia had not received any European Structural Funds in 2000-2006. The same methodology was used by De Miguel and Manresa (2008) [15] to study the effects of the withdrawal of the European financial support to agriculture in Extremadura on the main economic variables of this region. The last paper published on this topic and within this methodological framework is the one by Monrobel, Cámara, and Marcos (2012) [16], which analyzes, through a CGE model, the impact of the European Union Regional Policy on the Autonomous Region of Madrid in the period 2007-2013.

This work is organized as follows: Section 2 presents the model, Section 3 discusses the main results and Section 4 summarises the conclusions.

\section{The Model}

This section presents the CGE model used for the analysis. Following Cardenete and Sancho (2003) [17], this model is formed by 25 productive sectors obtained from an aggregation of the Input-Output Tables for Andalusia, where the domestic output of each sector $\left(X d_{j}\right)$ uses the output of the other sectors as factors:

$$
\begin{aligned}
& X d_{j}=\min \left(X_{1 j} / a_{1 j}, X_{2 j} / a_{2 j}, \cdots, X_{25 j} / a_{25 j}, V A_{j} / v_{j}\right), \\
& j=1,2, \cdots, 25
\end{aligned}
$$

In this equation, $X_{i j}$ represents the amount of good $i$ required for the domestic production of $\operatorname{good} j ; a_{i j}$ are the equivalents to technical coefficients in the framework of Input-Output analysis; $V A_{j}$ stands for the value added of sector $j$, and $v_{j}$ is the minimum amount of value added required to produce one unit of good $j$. 
On the following nesting level, the regional value added of each sector $j\left(V A_{j}\right)$ is the result of combining the primary factors (labour, $L$, and capital, $K$ ) by using a Leontief fixed coefficients technology:

$$
V A_{j}=\min \left(K_{j} / k_{j}, L_{j} / l_{j}\right), j=1,2, \cdots, 25
$$

The total output $\left(Q_{j}\right)$ is the result of combining the domestic output $\left(X d_{j}\right)$ with the equivalent imports $\left(X_{r o w}\right)$-which are considered imperfect substitutes of domestic production - by applying the already mentioned Leontief technology. In particular, the production of sector $j$ is given by:

$$
Q_{j}=\min \left(X d_{j}, \text { Xrow }_{j}\right), j=1,2, \cdots, 25
$$

The government taxes the transactions between the other economic agents to obtain public revenue $(R)$. It has an influence on the consumers' disposable income $(D P I)$, makes transfers to the private sector (TPS), and demands goods and services $\left(G D_{j}\right)$. The difference between revenues and payments represents the deficit or surplus of the administration.

In relation to investment and savings, the latter are considered an exogenous component, thus allowing investment to be defined endogenously. In the equilibrium situation, it is necessary to guarantee the macroeconomic equality between savings at the aggregated level and the total investment of the economy:

$$
\sum_{j=1}^{n} D I_{i} \text { pinv }=D A H O p i n v+D P+D P R M
$$

Finally, it is important to remark that the computable general equilibrium model here presented follows the traditional Walrasian equilibrium doctrine, now expanded to include the public and the foreign sectors.

In the Walrasian equilibrium the supply is equal to the demand, the productive factors (labour and capital) are considered as used at full capacity, in the case of labour factor the unemployment is included in the model, the levels of activity of both the government and the foreign sector are assumed to be fixed, allowing relative prices, the levels of activity of the productive sectors and the public and foreign deficits to function as endogenous variables.

Formally, the model reproduces a state of equilibrium of the Andalusian economy in which the supply and demand functions of all goods are obtained as a solution for the utility and profit maximisation problems. The result is a vector of prices of goods and factors, of levels of activity and taxes that satisfy the above-described conditions.

\section{Results}

To measure the impact of the European Structural funds on the Andalusian economy in 2007-2013, two different scenarios are compared: first, the current or "with-funds" scenario, which reflects the total amount of European Funds stipulated and received in this period; and, second, the hypothetical or "without-funds" scenario, in which the total amount of income earned through the structural funds received from the European Union these last seven years is removed. In order to do this, a corrector index is built and applied to the public sector demand variable in the CGE model. This index reflects the fall in the demand that results from the withdrawal of funds, establishing an alternative scenario that aims at reaching a new equilibrium in which all the conditions of the optimality model will be complied with.

Table 1 shows the expenditure planned for each type of Fund.

These are the results obtained with the simulations made on several macroeconomic variables.

Table 2 presents the rates of variation obtained by comparing the current scenario (in which European Funds are received) with a hypothetical scenario (which excludes all the European Funds received). This analysis was conducted for each of the components of the GDP expenditure, the GDP income, the disposable income and the total output. As a result, it is possible to say that the effect on the GDP of removing the entire amount of European Funds received in 2007-2013 amounts to a decline of around 15.5 percent of the GDP throughout these seven years, with GOS, investment and net foreign demand as the components most affected by the withdrawal of funds. During this period, a cumulative decline of around 16 percent of the disposable income and 1.3 percent of the total output is also observed as a consequence of withdrawing the funds.

An efficiency coefficient of the European Funds has been additionally calculated in order to compute the return obtained, in terms of GDP, by the European Funds received in Andalusia.

The result presented in Table 3 shows that the effi-

Table 1. Summary of European Funds received in 20072013 (thousand euros).

\begin{tabular}{cc}
\hline Instruments of Intervention & Total Funds \\
\hline Total European Regional Development Funds (ERDF) & $9,451,160$ \\
Total European Structural Funds (ESF) & $2,875,850$ \\
Cohesion Funds & 200,040 \\
European Agricultural Funds for Rural & $1,881,740$ \\
Development (EAFRD) & 176,700 \\
European Fisheries Funds (EFF) & $\mathbf{1 4 , 5 8 5 , 4 9 0}$ \\
\hline
\end{tabular}

Source: Ministry of Territorial Policy (2009) through the Ministry of Economy and Finance [18]. 
Table 2. Rates of variation of the main macroeconomic variables in 2007-2013 (thousand euros).

\begin{tabular}{cccc}
\hline $\begin{array}{c}\text { Macroeconomic } \\
\text { Variables }\end{array}$ & With Funds & $\begin{array}{c}\text { Without } \\
\text { Funds }\end{array}$ & $\begin{array}{c}\text { Rates of } \\
\text { Variation (\%) }\end{array}$ \\
\hline Consumption & $115,339,465$ & $99,471,368$ & -15.95 \\
Investment & $43,412,502$ & $32,860,646$ & -32.11 \\
Public Expenditure & $31,535,562$ & $30,923,823$ & -1.98 \\
Net Foreign Demand & $-40,082,470$ & $-33,132,695$ & -20.98 \\
GDP Expenditure & $\mathbf{1 5 0 , 2 0 5 , 0 5 9}$ & $\mathbf{1 3 0 , 1 2 3 , 1 4 2}$ & $-\mathbf{1 5 . 4 3}$ \\
$\begin{array}{c}\text { Labour Remuneration } \\
\text { Gross Operating }\end{array}$ & $\mathbf{5 5 , 6 2 2 , 3 1 4}$ & $55,622,313$ & 0.00 \\
Surplus (GOS) & $\mathbf{6 2 , 1 0 1 , 1 6 3}$ & $46,376,517$ & -33.91 \\
Tax Collection & $32,481,582$ & $28,124,312$ & -15.49 \\
GDP Income & $\mathbf{1 5 0 , 2 0 5 , 0 5 9}$ & $\mathbf{1 3 0 , 1 2 3 , 1 4 2}$ & $-\mathbf{1 5 . 4 3}$ \\
\hline $\begin{array}{c}\text { Total Output } \\
\text { Disposable Income }\end{array}$ & $\mathbf{1 4 2 , 3 8 2 , 8 4 7}$ & $\mathbf{1 2 2 , 7 9 4 , 1 9 4}$ & $-\mathbf{1 5 . 9 5}$ \\
\hline
\end{tabular}

Source: own elaboration.

Table 3. Efficiency coefficient of the European Funds in 2007-2013 (thousand euros).

\begin{tabular}{cc}
\hline Magnitudes & Total Amount \\
\hline GDP Without Funds & $130,123,142$ \\
GDP With Funds & $150,205,059$ \\
European Funds Received & $14,585,490$ \\
Efficiency Coefficient & $\mathbf{1 . 4}$ \\
$(\triangle$ GDP / Funds Received $)$ & \\
\hline
\end{tabular}

Source: own elaboration.

ciency coefficient accumulated in the period under study is 1.4, which means that, for every euro of European Funds entering the regional economy, 1.4 euros are obtained.

\section{Concluding Remarks}

This paper has analysed the withdrawal of European Funds from the Andalusian economy in the period 20072013, during which the region was classified as a Convergence region, a term that replaces that of Objective 1 region, used in previous funding periods.

The effect on the main macroeconomic variables of removing the entire amount of European Funds received during the period 2007-2013 is a decrease of around 15.5 percent of the GDP, 16 percent of the disposable income, and 1.3 percent of the total output along the period. Moreover, when the efficiency ratio of the European Funds in terms of GDP is calculated, the result obtained is 1.4 , which means that for every euro of European financial support received and added to the regional economy, 1.4 euros are produced.

In summary, and considered all the results herein presented, it is necessary to highlight the importance that the European financial support has for Andalusia in terms of growth, development and convergence, since all the variables analysed would suffer a sharp decline without the contribution of the European Funds, which indisputably have affected the growth of the region in the period under study.

\section{Acknowledgements}

The first author wishes to thank the funding received from projects MICINN-ECO2009-11857, SGR2009-5781 and SEJ479. Both authors thank the funding received from Project 092-2011 of the Centro de Estudios Andaluces (CENTRA).

\section{REFERENCES}

[1] M. A. Cardenete, M. C. Delgado and M. C. Lima, "The Structural Funds in Andalusia for the Programming Period 2014-2020: Time for Tightening Belts," European Planning Studies, 2013, doi:10.1080/09654313.2013.771622

[2] L. Walras, "Elementos de Economía Política Pura," Alianza Editorial, Madrid, 1874.

[3] K. J. Arrow and G. Debreu "Existence of an Equilibrium for a Competitive Economy," Econometrica, Vol. 22, No. 3, 1954, pp. 265-290. doi:10.2307/1907353

[4] A. Wald, "On Some Systems of Equations of Mathematical Economics," Econometrica, Vol. 19, No. 4, 1951, pp. 368-403. doi:10.2307/1907464

[5] L. W. McKenzie, "On the Existence of General Equilibrium for a Competitive Market," Econometrica, Vol. 27, No. 1, 1959, pp. 54-71. doi:10.2307/1907777

[6] H. Scarf, "The Computation of Economic Equilibria," with T. Hansen, Yale University Press, New Haven, 1973.

[7] J. Whalley, "A General Equilibrium Assessment of the 1973 United Kingdom Tax Reform," Economica, Vol. 42, No. 166, 1975, pp. 139-161. doi:10.2307/2553589

[8] J. Whalley, "The United Kingdom System, 1968-1970: Some Fixed Point Indications of its Economic Impact," Econometrica, Vol. 45, No. 8, 1977, pp. 1837-1858. doi: $10.2307 / 1914113$

[9] J. B. Shoven, "The Incidence and Efficiency Effects of Taxes on Income from Capital," Journal of Political Economy, Vol. 86, No. 6, 1976, pp. 1261-1284. doi: $10.1086 / 260511$

[10] P. K. Narayan, "Macroeconomic Impact of Natural Disasters on a Small Island Economy: Evidence from a CGE Model," Applied Economics Letters, Vol. 10, No. 11, 2003, pp. 721-723. doi:10.1080/1350485032000133372

[11] M. Llop and A. Manresa, "The General Equilibrium Ef- 
fects of social Security Contributions under Alternative Incidence Assumptions," Applied Economics Letters, Vol. 11, No. 13, 2004, pp. 847-850. doi: $10.1080 / 1350485042000258265$

[12] M. C. Lima and M. A. Cardenete, "The Effects of European Structural Funds in a Regional Economy: An Applied General Equilibrium Analysis," Applied Economic Letters, Vol. 14, No. 11, 2007, pp. 851-855. doi:10.1080/13504850600592630

[13] M. C. Lima and M. A. Cardenete, "The Impact of the European Structural Funds in the South of Spain: A CGE Approach," European Planning Studies, Vol. 16, No. 10, 2008, pp. 1445-1457. doi:10.1080/09654310802420169

[14] M. C. Lima, M. A. Cardenete and C. Usabiaga, "Andalucía y el MAC 2000-2006: Una Evaluación de Los Fondos Estructurales Recibidos," Papeles de Economía Española, No. 123, 2010, pp. 102-118.

[15] F. J. De Miguel and A. Manresa, "Removal of Farm Subsidies in a Regional Economy: A Computable General
Equilibrium Analysis," Applied Economics, Vol. 40, No. 16, 2008, pp. 16-18. doi:10.1080/00036840600949371

[16] J. R. Monrobel, A. Cámara and M. A. Marcos, "Modeling European Regional Policy 2007-2013: Applied General Equilibrium Analysis of the Economic Impact on the Madrid Region," European Planning Studies, Vol. 21, No. 2, 2013, pp. 264-280. doi:10.1080/09654313.2012.722925

[17] M. A. Cardenete and F. Sancho, "An Applied General Equilibrium Model to Assess the Impact of National Tax Changes on a Regional Economy," Review of Urban and Regional Development Studies, Vol. 15, No. 1, 2003, pp. 55-65. doi:10.1111/1467-940X.00064

[18] Ministerio de Política Territorial, "Perfil Económico y Financiero de las Comunidades Autónomas 2008. Andalucía," Secretaría de Estado de Cooperación Territorial, Dirección de Cooperación Autonómica, Subdirección General de Análisis de las Comunidades Autónomas, Madrid, 2009. 